\title{
Comparison of high- versus low-intensity community health worker intervention to promote newborn and child health in Northern Nigeria
}

\author{
This article was published in the following Dove Press journal: \\ International Journal of Women's Health \\ 25 October 2013 \\ Number of times this article has been viewed
}

\author{
Sally E Findley' \\ Omolara T Uwemedimo ${ }^{2}$ \\ Henry V Doctor ${ }^{1,3}$ \\ Cathy Green ${ }^{4}$ \\ Fatima Adamu ${ }^{5}$ \\ Godwin Y Afenyadu6 \\ 'Department of Population and \\ Family Health, Mailman School of \\ Public Health, Columbia University, \\ New York, NY, USA; ${ }^{2}$ Pediatric Global \\ Health Program, Cohen Children's \\ Medical Centre of New York, Division \\ of General Pediatrics, New Hyde \\ Park, NY, USA; ${ }^{3}$ Operations Research \\ Unit, Programme for Reviving Routine \\ Immunization in Northern Nigeria- \\ Maternal Newborn and Child Health \\ (PRRINN-MNCH), Abia State House, \\ Abuja, Nigeria; ${ }^{4}$ Health Partners \\ International, Waterside Centre, \\ Lewes, East Sussex, United Kingdom; \\ ${ }^{5}$ Social Development and Community \\ Engagement Unit, ${ }^{6}$ Operations \\ Research Unit, PRRINN-MNCH \\ Programme, Nassarawa GRA, Kano \\ State, Nigeria
}

Background: In Northern Nigeria, infant mortality rates are two to three times higher than in the southern states, and, in 2008, a partnership program to improve maternal, newborn, and child health was established to reduce infant and child mortality in three Northern Nigeria states. The program intervention zones received government-supported health services plus integrated interventions at primary health care posts and development of community-based service delivery (CBSD) with a network of community volunteers and community health workers (CHWs), who focus on educating women about danger signs for themselves and their infants and promoting appropriate responses to the observation of those danger signs, consistent with the approach of the World Health Organization Integrated Management of Neonatal and Childhood Illness strategy. Before going to scale in the rest of the state, it is important to identify the relative effectiveness of the low-intensity volunteer approach versus the more intensive CBSD approach with CHWs.

Methods: We conducted stratified cluster sample household surveys at baseline (2009) and follow-up (2011) to assess changes in newborn and sick child care practices among women with births in the five prior years (baseline: $\mathrm{n}=6,906$; follow-up: $\mathrm{n}=2,310$ ). The follow-up respondents were grouped by level of intensity of the CHW interventions in their community, with "low" including group activities led only by a trained community volunteer and "high" including the community volunteer activities plus CBSD from a CHW providing one-on-one advice and assistance. $t$-tests were used to test for significant differences from baseline to follow-up, and $F$-statistics, which adjust for the stratified cluster design, were used to test for significant differences between the control, low-intensity, and high-intensity intervention groups at follow-up. These analyses focused on changes in newborn and sick child care practices.

Results: Anti-tetanus vaccination coverage during pregnancy increased from $69.2 \%$ at baseline to $85.7 \%$ at follow-up in the intervention areas. Breastfeeding within 24 hours increased from $42.9 \%$ to $59.0 \%$ in the intervention areas, and more newborns were checked by health workers within 48 hours (from $16.8 \%$ at baseline to $26.8 \%$ at follow-up in the intervention areas). Newborns were more likely to be checked by trained health personnel, and they received more comprehensive newborn care. Compared to the control communities, more than twice as many women in intervention communities knew to watch for specific newborn danger signs. Compared to the control and low-intensity intervention communities, more mothers in the high-intensity communities learned about the care of sick children from CHWs, with a corresponding decline those seeking advice from family or friends or traditional birth attendants. Significantly fewer mothers did nothing when their child was sick. High-intensity intervention
Correspondence: Henry V Doctor Department of Population and Family Health, Mailman School of Public Health, Columbia University, 60 Haven Avenue, New York, NY 10032, USA

Email hvd2105@columbia.edu 
communities experienced the most decline. Those who did nothing for children with fever or cough declined from $35 \%$ to $30 \%$, and with diarrhea from $40 \%$ to $31 \%$. Use of medications, both traditional and modern, increased from baseline to follow-up, with no differentiation in use by intervention area.

Conclusion: The community-based approach to promoting improved newborn and sick child care through community volunteers and CHWs resulted in improved newborn and sick child care. The low-intensity approach with community volunteers appears to have been as effective as the higher-intensity CBSD approach with CHWs for several of the key newborn and sick child care indicators, particularly in the provision of appropriate home care for children with fever or cough.

Keywords: community health worker, newborn and child health, Nigeria

\section{Background}

Of the 7 million deaths of children under the age of 5 years that occurred worldwide in 2011, at least two-thirds could have been prevented by low-cost, integrated newborn and child health $(\mathrm{NCH})$ interventions. ${ }^{1,2}$ The majority of global childhood deaths, largely due to neonatal problems, pneumonia, diarrhea, and malaria, occur without any contact with the formal health system. Simply, most children die in their own homes. ${ }^{3}$ Correspondingly, recent evidence from the 2008 Lancet Alma-Ata series suggests that interventions focused on scaling-up community and household care, in particular, have had a significant impact on newborn and child survival. ${ }^{4}$ Such interventions have included promotion of early initiation of breastfeeding, early postnatal followup care of newborns, exclusive breastfeeding for at least 6 months, increasing recognition of danger signs of illness among caregivers, and case management of acute febrile illnesses during early childhood. ${ }^{2,3,5,6}$ As integrated maternal, newborn, and child health $(\mathrm{MNCH})$ packages are currently being delivered to-scale across many low-income countries, there has been an acceleration in the decline of global childhood mortality since $2000 .^{5}$

One out of nine children under 5 years will die each year in sub-Saharan Africa, and reductions in childhood mortality have been slower than in the rest of the world, including Southern Asia. ${ }^{1}$ While there are a myriad of factors that explain this regional disparity (eg, extreme poverty, low female education and autonomy, inadequate health system infrastructure), a major obstacle is the inaccessibility of human resources for health. ${ }^{7}$ Countries with a higher density of health professionals per capita have been found to have higher rates of infant and child survival. Sub-Saharan Africa has the lowest health worker density in the world, at 2.3 per 1,000 population. ${ }^{8}$ The relationship between health worker density and child survival is similarly manifest in the inequalities in child survival between the under-served rural areas and the urban areas with relatively higher health worker density. ${ }^{9}$ Based on these challenges, the use of community health workers (CHWs) has emerged as a solution with the strongest potential to strengthen primary health care delivery in sub-Saharan Africa. ${ }^{10,11} \mathrm{CHWs}$ are described as:

[...] members of the communities where they work, [who] should be selected by the communities, answerable to the communities for their activities, supported by the health system but not necessarily a part of its organization, and have shorter training than professional workers. ${ }^{12}$

The effective use of CHWs has the capacity to address the three major gaps in service delivery: coverage, equity, and quality. ${ }^{7}$ Limited data have suggested that this cadre of health workers is uniquely capable of reaching children most at risk: those from the poorest families; and those living in remote areas. ${ }^{4,13}$

In Nigeria, the most populous country in Africa and the country with the second-highest burden of child deaths in the world, the need to improve child survival is enormous. ${ }^{3}$ Further, within Nigeria, there are marked differentials in child mortality rates, with rates in the northern states two to three times higher than those in the southern states. ${ }^{14} \mathrm{In}$ response to this challenge, the Programme for Reviving Routine Immunization in Northern Nigeria (PRRINN) was established in 2006 in four northern states of Nigeria (Jigawa, Katsina, Yobe, and Zamfara) and then, in 2008, expanded to include MNCH (PRRINN-MNCH). The program is comprehensive, encompassing multiple aspects of the health system, including human resources, health governance, health information, strengthening of clinical services, and community engagement, in order to reduce maternal, newborn, and child mortality. The program is focused, amongst other things, on improving access to quality emergency obstetrics care (EOC) by building the capacity of selected facilities to provide comprehensive and basic emergency obstetrics care services. One comprehensive EOC and four basic EOC facilities with referral linkages constitute a cluster. Attention is also paid to training of health care workers at all levels in this cluster, as well as strengthening demand for health care services within communities served by these designated emergency care facilities. The program utilizes an operations research 
approach that promotes evidence-based quality improvement of ongoing program activities.

A key element of this integrated strategy is the development of a network of CHWs, who bridge the gap between the household and the health facility. This paper will focus on the effect of the CHW intervention within PRRINN-MNCH from 2009 to 2011. Specifically, we will report changes in newborn and child health care knowledge and behaviors among caregivers and changes in newborn and child morbidity from the baseline (2009) to the follow-up (2011), with the latter split into low- and high-intervention areas.

\section{Methods}

\section{Intervention design}

The focus of this study is on the impact of the $\mathrm{MNCH}$ interventions, which were implemented in three of the four northern Nigerian states in which PRRINN has expanded its MNCH activities, namely Katsina, Yobe, and Zamfara, with respective populations of 5.8, 2.3, and 3.3 million, according to the 2006 population census of Nigeria. ${ }^{15}$ The program design focuses on improving $\mathrm{MNCH}$ care by clusters of local government areas (LGAs) per state, which each comprise a catchment area for EOC services. A total of 15 LGAs were selected as the first intervention clusters, with four to six LGAs per state. The cluster approach was based on the World Health Organization (WHO) comprehensive EOC model. ${ }^{16}$ Within the program, the cluster approach uses one comprehensive EOC facility per 500,000 people. Making referrals to this comprehensive EOC facility are four basic EOC facilities (each serving 100,000 people, with the comprehensive EOC facility serving the other 100,000 people) and eight " $24 / 7$ " facilities providing maternal care. The remaining LGAs had statewide policy changes without focused clinical or community activities to improve health system infrastructure and $\mathrm{MNCH}$ care demand.

The health system-strengthening component of the intervention includes upgrading EOC services within local health facilities, midwife training and posting through the Nigerian government's Midwife Service Scheme, establishing planning and management techniques within existing facilities, and establishing the "Primary Health Care Under One Roof" system, which consolidates and coordinates the different components of primary care in one health clinic or post. Complementing these supply-side changes are activities that create demand for MNCH services. Selected groups of villages served by primary care facilities linked to the upgraded EOC facility participate in a community engagement process, which aims to increase awareness, knowledge, and practices of healthy behaviors in response to $\mathrm{MNCH}$ barriers. The core of this process is a community discussion-group methodology, facilitated by trained community volunteers (CVs), which provides a space for reflection and problem-solving for the most prevalent $\mathrm{MNCH}$ problems affecting the community. $\mathrm{CVs}$ are recruited in each community and trained to do outreach and social mobilization, emphasizing the use of community discussion groups and jingles and other visual-auditory cues for education about critical $\mathrm{MNCH}$ issues, such as danger signs for a pregnancy or the timing of childhood vaccinations. In addition to these health education roles, the CVs also aid in identifying atrisk women and children and referring them to the nearest facility for care.

The CVs were nominated by other community members and, in some cases, by traditional leaders. Training of CVs was community based and used a cascade or train-the-trainers model, with core trainers training CVs who, in turn, train new volunteers. The participatory training methodology was underpinned by key principles of adult learning and took trainees through a learning cycle, starting with discussions and reflection of personal experiences ( $\mathrm{sad}$ memories), leading to consideration of potential responses/solutions, and eventually resulting in action. Body memory tools (eg, use of fingers to demonstrate the number of immunization visits required for children at specific ages, or mimicking movements of the body when affected by different danger signs) helped trainees remember key facts and were a highly effective aid to learning. Demonstration by a core trainer followed by repetitive practice sessions reviewed by other trainees was also highly effective. The $\mathrm{CV}$ training focused both on core content and on the facilitation techniques needed to engage appropriately with the community.

Between 2010 and 2013, almost 30,000 CVs, primarily women, were recruited, mobilized and supported in their work in over 3,600 communities. Community discussiongroup participants are encouraged and supported to establish emergency systems by which to tackle key barriers to access to and affordability of $\mathrm{MNCH}$ services, including establishment of blood donor groups, community emergency savings schemes, community emergency transport schemes, and a "mother's helpers" system. Members of the discussion groups are encouraged to share what they know with their families and peers between sessions, leading to rapid saturation of the entire community with new ideas. This work is reinforced by mass communication activities, including the use of radio jingles to promote birth preparedness or childhood immunizations. Because the CVs focus on outreach and 
engagement through group discussions without any home visits or care activities, communities with CVs only were designated as having the low-intensity $\mathrm{CHW}$ intervention.

In 2010, the year before this evaluation, the program also developed a small cadre of CHWs, community-based health workers providing selected primary health services directly to families through rotating visits or extended availability through residence in the communities. These CHWs were recruited among unemployed but previously trained Junior Community Health Extension Workers trained by the state Schools of Health Technology, who were then given 2 weeks of additional training and toolkits to enable them to make home visits, engage mothers using supportive communication techniques, provide basic preventive antenatal care and $\mathrm{NCH}$ services, basic treatment services through WHO Integrated Management of Neonatal and Childhood Illness strategy, and refer to the primary health care facility for treatment as needed. These community-based health workers are provided with transport to enable them to visit communities on a regular schedule, and they spend most of their time visiting families and providing preventive and basic treatment services in the community. At the time of the evaluation reported here, these CHWs were active in 25 communities, all of which also had CVs supporting their work through community education and mobilization. Communities with $\mathrm{CVs}$ and $\mathrm{CHWs}$ providing $\mathrm{CBSD}$ were designated as receiving the high-intensity $\mathrm{CHW}$ intervention.

\section{Evaluation design}

The assessment of the impact of the CBSD programs uses a quasi-experimental design using pre- and post-intervention household surveys in the intervention and control communities. The pre-intervention or baseline household survey (BHS) was conducted in 2009 and the post-intervention household survey or follow-up household survey (FHS) was conducted in 2011. This program is grounded in the hypothesis that this multi-component intervention will lead to changes in health knowledge and behaviors and attitudes toward existing services, resulting in increased service utilization and improved health outcomes. The evaluation of the impact of this integrated $\mathrm{MNCH}$ package takes into account both availability of the program and actual individual participation in any of the program's community-based service activities. Availability of the program activities was assessed by comparison of intervention (categorized as low and high) and control areas. Low-intervention communities are defined as communities with community engagement activities by $\mathrm{CVs}$ only, whereas high-intervention communities are those with community engagement by CVs plus CBSD strategies. Individual exposure to the program was assessed by the women's responses to questions eliciting sources of information or health care advice, which allowed for different sources corresponding to the alternative CBSD strategies. The study was approved by state ethics review committees in each of the three states, as both cross-state and individual state approval. These ethics review committees are certified by the Nigerian Federal Government's National Health Research Ethics Committee to review and approve health research protocols for their states.

\section{Study sample}

The sampling plan was a stratified two-stage cluster sample, with oversampling of individuals in the $\mathrm{MNCH}$ intervention clusters. Individuals from $\mathrm{MNCH}$ clusters were oversampled using a ratio of $2: 1$, because $\mathrm{MNCH}$ clusters cover a significantly lower proportion of the population of each state. Oversampling therefore provided a sufficient sample in the intervention areas to assess the impact of key elements within the intervention package on the key $\mathrm{MNCH}$ outcomes. The primary sampling unit for this sample was the LGA, of which there were 24 in the BHS and 15 in the FHS. For the FHS, the same intervention LGAs as in the BHS were included, with the exception of LGAs of the state capitals (considered not to be an appropriate control for the largely rural intervention). The LGAs comprising the state capitals were included only during the baseline to assess the differences in services provided to residents patronizing urban versus rural facilities. This enabled the team to devise appropriate strategies for referral from rural to urban facilities. The state capitals were excluded in the analyses reported here. The number of households selected per LGA was proportional to the size of the LGA. The study was designed with an $80 \%$ power to detect even the smallest change (ie, $2.5 \%$ change) in the percentage of women delivering with the assistance of skilled birth attendants between the BHS and the FHS. The BHS was designed to be representative of all ever-married women in the household and required a sample of 5,560 households, while the FHS was designed to be representative only of ever-married women with a birth in the previous 5 years, requiring a sample of only 2,310 households. In the BHS, the sample of 5,560 households was $0.7 \%$ to $9.8 \%$ per LGA, while, for the FHS, the 2,310 households comprised $3.1 \%$ to $13.1 \%$ of all households.

Within the LGA, the sample of households was allocated to intervention and control communities in proportion to the size of the community or village. The sampling fraction for each community was determined by information on the total 
households from the community leader. Households within each selected community were randomly sampled using a procedure similar to that used in the WHO-Expanded Program on Immunization cluster surveys, ${ }^{17}$ namely by numbering then sampling households according to the community sampling fraction along randomly selected paths leading out from the center of the village.

The household was the ultimate sampling unit. In compounds that comprised one to three households, one household was randomly chosen for interviews; in compounds with four to six households, two were surveyed; in compounds with seven or more households, three were surveyed. Within each randomly selected household, in the baseline survey, all ever-married women of childbearing age (15-49 years) were interviewed, whereas in the FHS only one ever-married woman with at least one child born in the last 5 years was selected for interview. In the BHS, there were 6,842 women with successfully completed interviews, while, in the FHS, there were 2,310 completed interviews.

Interviewers who had completed secondary school or higher were selected and trained to visit the selected women at home and administered a questionnaire that included translation of key concepts and terms in the local languages (eg, Hausa, Kanuri). Most of the interviewers were female, responding to cultural expectations and beliefs that encourage females to respond to female interviewers. In both the BHS and FHS, the questionnaires used adopted some of the close-ended questions from the 2008 Demographic and Health Survey ${ }^{14}$ to allow comparison of results with other national- or state-level data. Questions were modified in line with the program goals and focused on a series of topics related to perceptions, knowledge, and practices related to $\mathrm{MNCH}$ outcomes. Specifically, the topics included issues related to information such as age, parity, economic status, literacy in any language, wife rank (sequence in polygamous marriage), antenatal care and delivery characteristics, infant and child mortality, source of health advice for the woman or the baby during last pregnancy, and experience of labor and delivery complications. Among other things, the survey also collected information on husband-wife communication about MNCH issues.

\section{Analysis}

Comparable data sets were generated from the BHS and FHS, including only ever-married respondents who had had a birth in the previous 5 years. Respondents were assigned to the control or intervention groups based on the level of PRRINN$\mathrm{MNCH}$ program intervention at the time of the survey. For the BHS, which was pre-intervention, the intervention LGAs included all LGAs in the first cluster receiving comprehensive emergency obstetrical care upgrades and related community engagement activities, while the balance were control LGAs. The FHS included the same intervention LGAs; LGAs that had been control in the BHS but had started to receive the intervention by the time that the FHS was administered were shifted to the intervention category. The intervention respondents were further classified as receiving the highintensity intervention if they were in communities with the pilot CBSD program with CHWs, while the remainder of the intervention communities was designated as low-intensity intervention communities. The dependent variables were the key health behaviors pertaining to newborn care and care of sick children. The two sets of survey data were separately analyzed using sampling weights based on the intervention and control areas. We examined changes in the proportion with the designated $\mathrm{MNCH}$ behavior or outcome, and compared all pre-intervention responses (all BHS) with the post-intervention responses from the FHS, namely intervention only, both high and low intensity. We then assessed the degree to which the different intervention groups differed at follow-up (control versus low intensity versus high intensity) using the $F$-statistic, adjusted for the complex sampling design of the FHS (15 primary sampling unit and three strata [control, low-intensity intervention, high-intensity intervention]). Analyses were performed using Stata (v 12.0; Statacorp, College Station, TX, USA) and SPSS software (v 19.0; IBM Corporation, Armonk, NY, USA).

\section{Results}

\section{Respondent characteristics}

The women interviewed in the FHS were younger and of lower social status, characteristics often associated with poor access to health care workers or services. In both surveys, most women interviewed were between the ages of 20 and 34 years, but there was a shift toward slightly younger ages in the FHS (see Table 1). Virtually all women interviewed were currently married, and about $80 \%$ were monogamously married. Over $80 \%$ of women had had no formal schooling, and among those with some schooling, there were fewer women at follow-up who had attended higher than primary school $(26.5 \%$ at follow-up versus $47.0 \%$ at baseline). The majority of women in both surveys could not read or write in Hausa, the primary language in Northern Nigeria. Nearly half of the women (47.8\%) said in the FHS that they were housewives, compared to only $30.3 \%$ in the BHS. Just under half (44\% in both surveys) 
Table I Background characteristics of respondents, Northern Nigeria, 2009 versus 2011

\begin{tabular}{|c|c|c|}
\hline $\begin{array}{l}\text { Background } \\
\text { characteristic }\end{array}$ & $\begin{array}{l}\text { BHS } 2009 \\
\text { n (\%) }\end{array}$ & $\begin{array}{l}\text { FHS 20I I } \\
\text { n (\%) }\end{array}$ \\
\hline \multicolumn{3}{|l|}{ Age group (years) } \\
\hline $15-19$ & $344(4.7)$ & $179(7.8)$ \\
\hline $20-24$ & $820(11.1)$ & $529(22.9)$ \\
\hline $25-29$ & $1,417(19.2)$ & $608(26.3)$ \\
\hline $30-34$ & $1,618(22.0)$ & $526(22.8)$ \\
\hline $35-39$ & $1,176(16.0)$ & $281(12.2)$ \\
\hline $40-44$ & $1,015(13.8)$ & 147 (6.4) \\
\hline $45-49$ & $982(13.3)$ & $29(1.3)$ \\
\hline \multicolumn{3}{|l|}{ Marital status } \\
\hline Married & $6,664(97.2)$ & $2,288(99.1)$ \\
\hline Widowed & $78(I . I)$ & II (0.5) \\
\hline Divorced or separated & $115(1.7)$ & $10(0.4)$ \\
\hline \multicolumn{3}{|l|}{ Rank of wife } \\
\hline Ist & $5,40 \mathrm{I}(80.6)$ & I $746(76.6)$ \\
\hline 2nd & $1,128(16.8)$ & $427(18.7)$ \\
\hline $3 r d+$ & $175(2.7)$ & $101(4.7)$ \\
\hline \multicolumn{3}{|l|}{ Formal education } \\
\hline Yes & $1,293(18.8)$ & $50 \mathrm{I}(16.5)$ \\
\hline No & $5,593(81.2)$ & $\mathrm{I}, 358(83.5)$ \\
\hline \multicolumn{3}{|l|}{ Level of formal education } \\
\hline Primary & $713(53.0)$ & $317(63.5)$ \\
\hline Secondary & $466(34.7)$ & $72(14.4)$ \\
\hline Post-secondary & $166(12.3)$ & $110(22.1)$ \\
\hline \multicolumn{3}{|c|}{ Reading and writing in Hausa } \\
\hline Not at all & $5,373(78.1)$ & $2,045(88.5)$ \\
\hline With difficulty & $644(9.4)$ & $|3|(5.9)$ \\
\hline Easily & $864(12.6)$ & $112(4.7)$ \\
\hline \multicolumn{3}{|l|}{ Occupation } \\
\hline Food processing & $2,480(36.2)$ & $664(28.7)$ \\
\hline Agricultural processing & $310(4.5)$ & $132(5.7)$ \\
\hline Farming & $249(3.6)$ & $230(10.0)$ \\
\hline Trading/selling & $1,200(17.5)$ & $655(28.3)$ \\
\hline Housewife & $2,079(30.3)$ & $\mathrm{I}, 105(47.8)$ \\
\hline Other & $534(7.8)$ & $149(6.4)$ \\
\hline \multicolumn{3}{|l|}{ Cellphone ownership } \\
\hline Yes & $543(7.9)$ & $667(28.9)$ \\
\hline No & $6,363(92.1)$ & I,643 (7I.I) \\
\hline Total & 6,906 & 2,310 \\
\hline
\end{tabular}

Abbreviations: BHS, baseline household survey; FHS, follow-up household survey.

reported working in agriculture, and only a minority engaged in trading $(17.5 \%$ in the BHS and $28.3 \%$ in the FHS). Women interviewed with the FHS were also more likely to have access to a cell phone (7.9\% versus $28.9 \%$, BHS versus FHS, respectively).

The majority of the households (about $80 \%$ in both surveys) included only one family, but among households with more than one family in the compound, there was an average of 2.5 families living together. There were an average of four women living in each household, and, of these women, on average, 1.5 had given birth within the preceding year.

\section{$\mathrm{NCH}$ outcomes}

More women had adopted recommended newborn care practices at follow-up compared to at baseline. At follow-up, more infants were protected from tetanus. The proportion of women who received anti-tetanus vaccinations increased significantly from a baseline of $69.2 \%$ to $84.6 \%$ and $87.6 \%$ in low and high intervention areas, respectively, as compared with an increase to $81.1 \%$ in the control area (Table 2). The proportion of newborns who were breastfed within 24 hours of birth significantly improved from a baseline of $42.9 \%$, and to a greater extent in the low intensity (59.1\%) and high intensity $(61.1 \%)$ areas, as compared with $56.1 \%$ in the control area. From BHS to FHS, there was no significant change in the proportion of newborns checked by a health worker within 48 hours of birth in the control area, but there were significant increases for the low- and high-intensity intervention areas, from $16.8 \%$ at baseline to $25.6 \%$ in the low-intensity areas and to $28.0 \%$ in the high-intensity areas. At follow-up, significantly more of these newborns had been checked by a nurse/midwife or a CHW. As shown in Figure 1, at follow-up in 2011, women were providing more comprehensive newborn care for their infants, with greater improvements in the low- than in the high-intensity intervention areas $(F=4.972, P=0.019)$. Compared to the BHS, in the FHS the largest increases in newborn care activities were washing the baby with warm water (from $39.6 \%$ to $58 \%$ in both intervention areas); cord care (from $7.0 \%$ to $29.8 \%$ and $34.9 \%$ in the low- and high-intensity intervention areas, respectively); breastfeeding within 8 hours (from $15.6 \%$ to $45.7 \%$ and $50.9 \%$, respectively); and newborn vaccinations (from $3.1 \%$ to $22.5 \%$ and $22.6 \%$, respectively). At follow-up, significantly fewer women had no one to advise them on the care of their newborn, from $31.9 \%$ at BHS down to $25.7 \%$ in the control areas and $18.9 \%$ in the high-intensity intervention areas (and no change in the low-intensity areas) $(t=4.93)$. The other major change was a shift from relying on traditional birth attendants (TBAs) for information about newborn care (from $48.4 \%$ to $8.7 \%$ [low intervention] and 5.5\% [high intervention]) to CHWs (from $6.8 \%$ to $12.4 \%$ in the low-intervention areas and $19.4 \%$ in the high-intervention areas). The impact of the community discussion groups was seen in the large share of women learning about newborn care from women's groups, friends, and family.

At follow-up, most women knew at least one of the newborn danger signs, with the most commonly known danger sign being high fever, known by $83 \%-84 \%$ of women, regardless of the level of intervention they had 
Table 2 Newborn care for the most recent birth, by intervention intensity, Northern Nigeria, 2009 versus 2011

\begin{tabular}{|c|c|c|c|c|c|c|}
\hline Characteristic & $\begin{array}{l}\text { BHS 2009, } \\
\%(n)\end{array}$ & $\begin{array}{l}\text { Control 20II, } \\
\%(n)\end{array}$ & $\begin{array}{l}\text { Low intensity } \\
2011, \%(n)\end{array}$ & $\begin{array}{l}\text { High intensity } \\
2011, \%(n)\end{array}$ & $\begin{array}{l}F(P) \\
\text { Control vs } \\
\text { low intensity vs } \\
\text { high intensity }\end{array}$ & $\begin{array}{l}t(P) \\
\text { BHS vs FHS }\end{array}$ \\
\hline Mother had anti-tetanus vaccine & $\begin{array}{l}69.2 \\
(1,335)\end{array}$ & $\begin{array}{l}81.1 \\
(132)\end{array}$ & $\begin{array}{l}84.6 \\
(494)\end{array}$ & $\begin{array}{l}87.6 \\
(250)\end{array}$ & $\begin{array}{l}1.018 \\
(0.339)\end{array}$ & $\begin{array}{l}50.1 \\
(0.000)\end{array}$ \\
\hline First breastfeeding within 24 hours & $\begin{array}{l}42.9 \\
(1,335)\end{array}$ & $\begin{array}{l}56.1 \\
(399)\end{array}$ & $\begin{array}{l}59.1 \\
(1,122)\end{array}$ & $\begin{array}{l}61.1 \\
(416)\end{array}$ & $\begin{array}{l}0.138 \\
(0.830)\end{array}$ & $\begin{array}{l}14.3 \\
(0.000)\end{array}$ \\
\hline $\begin{array}{l}\text { First postnatal check within } \\
48 \text { hours }\end{array}$ & $\begin{array}{l}16.8 \\
(1,335)\end{array}$ & $\begin{array}{l}15.5 \\
(71)\end{array}$ & $\begin{array}{l}25.6 \\
(258)\end{array}$ & $\begin{array}{l}28.0 \\
(143)\end{array}$ & $\begin{array}{l}1.164 \\
(0.328)\end{array}$ & $\begin{array}{l}4.90 \\
(0.000)\end{array}$ \\
\hline Person checking newborn & & & & & 3.433 & 42.1 \\
\hline Nurse/midwife & 34.5 & 59.6 & 41.0 & 35.7 & $(0.015)$ & $(0.000)$ \\
\hline $\mathrm{CHW}$ - health post & 4.7 & 19.2 & 29.1 & 48.2 & & \\
\hline $\mathrm{CHW}$ - outreach & NA & 9.6 & 13.4 & 4.8 & & \\
\hline TBA & 40.8 & $-^{c}$ & $--^{c}$ & NA & & \\
\hline Other & $\begin{array}{l}20.0 \\
(1,335)\end{array}$ & $\begin{array}{l}11.8 \\
(94)\end{array}$ & $\begin{array}{l}16.6 \\
(337)\end{array}$ & $\begin{array}{l}11.3 \\
(168)\end{array}$ & & \\
\hline Care provided to the newborn & & & & & 4.972 & 24.7 \\
\hline No special newborn care & NA & 3.6 & 0.9 & 0.0 & $(0.019)$ & $(0.000)$ \\
\hline Cord care & 7.0 & 5.7 & 29.8 & 34.9 & & \\
\hline Washed baby & 39.1 & 39.6 & 58.5 & 58.1 & & \\
\hline Kept baby warm (kangaroo) & 16.8 & 13.2 & 21.3 & 21.7 & & \\
\hline Breastfed immediately & 15.6 & 28.3 & 45.7 & 50.9 & & \\
\hline Watched for danger signs & 20.0 & I5. I & 20.6 & 19.8 & & \\
\hline Registered the birth & NA & 3.8 & 5.1 & 5.7 & & \\
\hline Newborn vaccination & 3.1 & 24.5 & 22.5 & 22.6 & & \\
\hline Weighed baby & 15.1 & 3.8 & 3.8 & 3.8 & & \\
\hline Watched for high fever & $\begin{array}{l}\text { NA } \\
(I, 44 I)\end{array}$ & $\begin{array}{l}11.3 \\
(404)\end{array}$ & $\begin{array}{l}24.3 \\
(1,126)\end{array}$ & $\begin{array}{l}23.4 \\
(418)\end{array}$ & & \\
\hline Source of information about & & & & & 1.330 & 4.93 \\
\hline newborn care ${ }^{d}$ & & & & & $(0.28 I)$ & $(0.000)$ \\
\hline No one & 31.9 & 25.7 & 31.6 & 18.9 & & \\
\hline Nurse/midwife & 25.0 & 6.0 & 7.1 & 7.9 & & \\
\hline $\mathrm{CHW}$ in health post & 6.8 & 3.5 & 8.4 & 14.4 & & \\
\hline $\mathrm{CHW}$ in outreach & NA & 3.7 & 4.0 & 5.0 & & \\
\hline TBA & 48.4 & 15.2 & 8.7 & 5.5 & & \\
\hline Family/friends & NA & 39.4 & 21.5 & 19.4 & & \\
\hline Drug vendor/chemist & NA & 3.2 & I.I & 0.0 & & \\
\hline Other & 1.8 & 0.3 & 0.5 & 0.0 & & \\
\hline Total & 6,208 & 404 & 1,126 & 418 & & \\
\hline
\end{tabular}

Notes: F-statistic is comparable to the chi-square statistic, but is corrected for the design effect of clustering used in the household survey sample design. ${ }^{a}$ Community volunteer only; 'bommunity volunteer plus $\mathrm{CHW}$; ${ }^{\mathrm{c}}$ not computed due to too few cases; ${ }^{\mathrm{d}}$ the person checking the newborn and counseling the mother after delivery. Abbreviations: BHS, baseline household survey; CHW, community health worker; FHS, follow-up household survey; NA, not applicable (response item not collected in the survey); TBA, traditional birth attendant; vs, versus.

experienced $(F=0.182, P=0.825)$ (Table 3). For almost all the other danger signs, however, women living in the intervention communities were more aware than those in the control communities. Women in the low- and high-intensity communities were more likely to know that convulsions or "fitting," jaundice, difficult or fast breathing, and inability to suckle were danger signs indicating that they needed to seek medical attention quickly $(F$-statistic with $P<0.10$ for all of these). About half (47.2\%) of the newborns demonstrated at least one of these danger signs during the first 6 weeks of life, with no difference in the frequency between control, low-intervention, and high-intervention areas. Although results were not statistically significant, of those with one of the danger signs, the most common danger sign was high fever, followed by diarrhea and then swollen stomach.

One-third (32.6\%) of the households reported a sick child (under 5 years) in the month prior to the survey. There were no significant differences in the proportion of sick children by intervention intensity (see Table 3 ). The most common illnesses were diarrhea with or without malnutrition (34\%-45\%), fever (presumed to be malaria, $25 \%-28 \%$ ), 


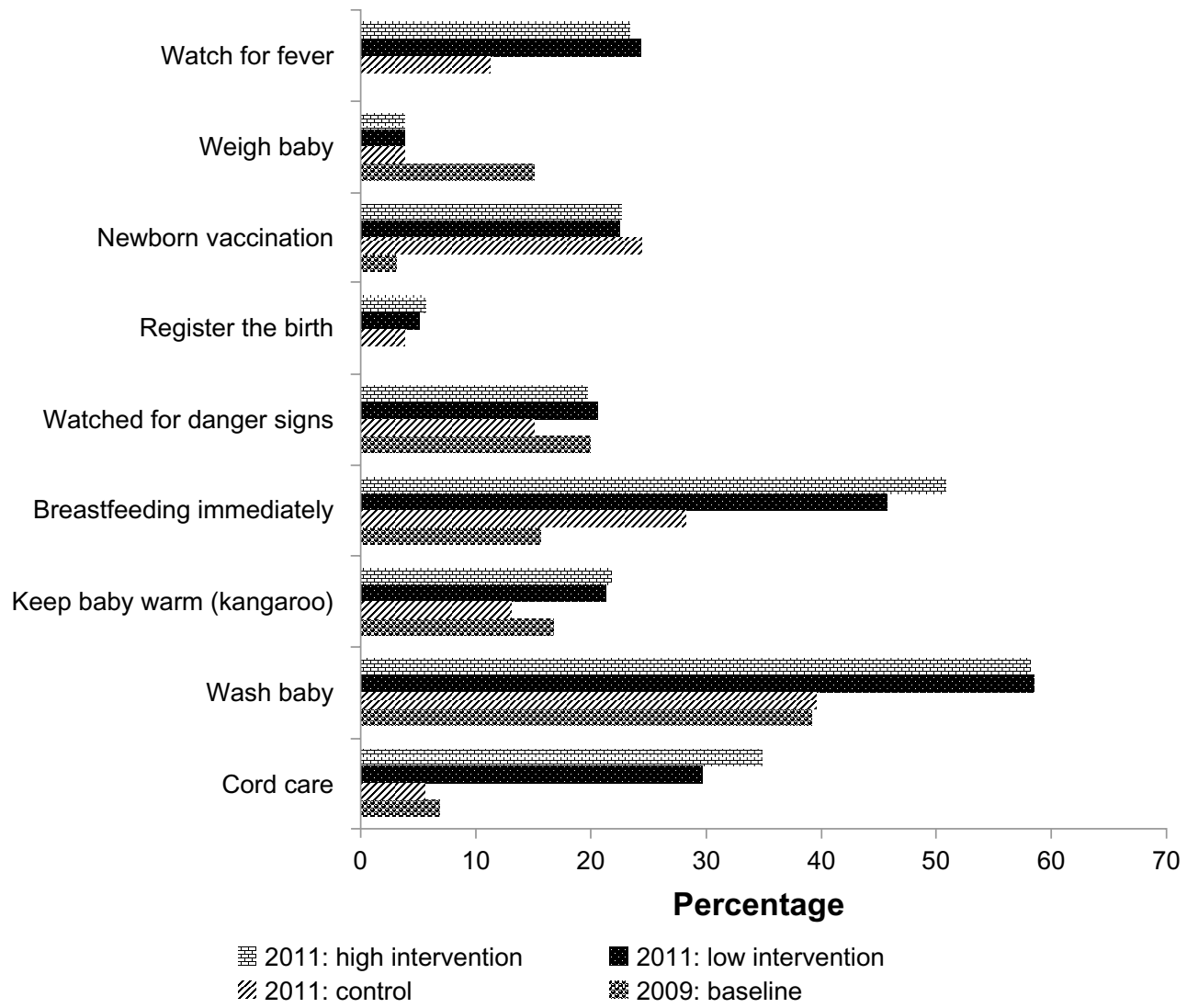

Figure I Newborn care activities (\%) by intervention intensity, Northern Nigeria 2009 and 201 I.

Note: Differences in newborn care activities are statistically significant for the baseline and follow-up household survey categories $\left(\chi^{2}=88.46, P=0.000\right)$.

and fever and cough (presumed to be malaria and/or pneumonia, 31\%-38\%). The reported illness prevalence rates were slightly higher in the high-intervention than in the low-intervention communities.

Between the BHS and FHS in 2011, there was a shift in the source of advice about the care of sick children (Table 3). While not significant $(F=1.872, P=0.111$ ), more women in the intervention communities knew about the care of their sick children, with only $18.9 \%$ and $31.6 \%$ in the high- and low-intervention communities, respectively, and $25.7 \%$ in the control areas having no one to teach them about the care of their sick children. More women learned how to care for sick children from CHWs, both at the health post and in the community, with CHWs providing this information to $10.7 \%$ in the control communities and $19.2 \%$ and $27.9 \%$ in the lowand high-intervention communities, respectively. Fewer relied on family and friends in the intervention communities, $27.3 \%$ and $23.6 \%$ (low and high intensity) versus $35.7 \%$ in the control communities. In the intervention communities, fewer women went to a TBA or drug vendor/chemist for advice on treating a sick child.
At baseline, over one-third of the mothers with sick infants (fever or cough or diarrhea) reported doing nothing when they observed that their child was sick. By follow-up, this was significantly lower in the intervention areas (27\% to $32 \%)(t=-2.68$ for fever/cough and $t=-3.88$ for diarrhea). As shown in Table 4, significantly more women in the highintensity intervention communities gave fluids and oral rehydration salts (ORS) at home to their child with fever or cough, as well as ORS to their child with diarrhea. Approximately one in ten mothers gave their child cough medicine for either fever/cough or diarrhea, without any difference in this pattern by intervention area. Between the BHS and FSH, the reported use of traditional medicine or herbs for fever/ cough or diarrhea almost doubled, significantly more than at baseline, but there were no significant differences in the use of traditional medicines or herbs by intervention area.

The largest changes in care for sick children were seen in the use of medications. The use of analgesics for fever/ cough rose significantly from from $39 \%$ (BHS) to $44 \%$ (highintensity) to $62 \%$ (control) $(t=7.09$ ), while, for diarrhea, analgesic use increased from from $30 \%$ (BHS) to $42 \%$ (highintensity) to $57 \%$ (control) ( $t=7.21$ ). Similarly, antibiotic use 
Table 3 Knowledge of and response to newborn danger signs and illness episodes of children under 5 years of age by intervention intensity, Northern Nigeria, 201 I

\begin{tabular}{|c|c|c|c|c|}
\hline $\begin{array}{l}\text { Newborn danger sign knowledge } \\
\text { and response type }\end{array}$ & $\begin{array}{l}\text { Control 20I I } \\
(\%)\end{array}$ & $\begin{array}{l}\text { Low } \\
\text { intensity }\end{array}$ & $\begin{array}{l}\text { High } \\
\text { intensity }\end{array}$ & $\begin{array}{l}F(P) \\
\text { Control vs low intensity } \\
\text { vs high intensity }\end{array}$ \\
\hline \multicolumn{5}{|l|}{ Knowledge of each newborn danger sign } \\
\hline None known & 9.8 & 8.8 & 11.5 & $0.543(0.56 \mathrm{I})$ \\
\hline \multicolumn{5}{|l|}{ Known } \\
\hline High fever & 83.2 & 83.4 & 84.7 & $0.182(0.825)$ \\
\hline Stiff neck, fitting, or convulsions & 14.6 & 31.6 & 23.3 & $2.827(0.091)$ \\
\hline Jaundice & 6.7 & 15.5 & 18.9 & $3.081(0.066)$ \\
\hline Difficult/fast breathing & 5.6 & 25.3 & 19.3 & $5.404(0.021)$ \\
\hline Not able to suckle/refusal to feed & 6.3 & 17.9 & 14.6 & $3.408(0.051)$ \\
\hline Diarrhea/dehydration/sunken soft spot & 21.6 & 26.7 & 33.2 & $0.647(0.5 \mid 2)$ \\
\hline$n$ & 297 & 771 & 339 & \\
\hline \multicolumn{5}{|l|}{$\begin{array}{l}\text { Observation of specific danger signs in } \\
\text { newborns ( }<6 \text { weeks old) }\end{array}$} \\
\hline High fever & 25.4 & 29.6 & 30.9 & I. $126(0.337)$ \\
\hline Stiff neck, fitting, or convulsions & 4.5 & 4.5 & 5.8 & $0.279(0.757)$ \\
\hline Swollen stomach & 16.5 & 17.9 & 14.2 & $0.612(0.550)$ \\
\hline Diarrhea & 14.5 & 18.0 & 19.7 & $0.830(0.426)$ \\
\hline Difficult/fast breathing & 5.0 & 6.4 & 9.4 & $\mathrm{I} .634(0.223)$ \\
\hline Not able to suckle/refusal to feed & 6.5 & 6.0 & 7.2 & $0.216(0.759)$ \\
\hline $\mathrm{n}$ & 401 & 1,125 & 417 & \\
\hline Source of advice on care of sick children & & & & $1.872(0.11 \mathrm{I})$ \\
\hline Nurse/midwife & 8.0 & 8.0 & 7.9 & \\
\hline $\mathrm{CHW}$ in health post & 6.0 & 14.7 & 24.5 & \\
\hline $\mathrm{CHW}$ in outreach & 4.7 & 4.5 & 3.4 & \\
\hline TBA & 6.7 & 5.0 & 0.7 & \\
\hline Family/friends & 35.7 & 27.3 & 23.6 & \\
\hline Drug vendor/chemist & 3.2 & I.I & 0.0 & \\
\hline Traditional healer/other & 0.3 & 0.5 & 0.0 & \\
\hline No one mentioned & 28.2 & 28.8 & 21.6 & \\
\hline $\mathrm{n}$ & 401 & $\mathrm{I}, \mathrm{I} 24$ & 416 & \\
\hline \multicolumn{5}{|l|}{$\begin{array}{l}\text { Specific acute illness episodes in } \\
\text { past month, children }<5 \text { years }\end{array}$} \\
\hline Fever only & 24.9 & 24.5 & 28.1 & $0.273(0.698)$ \\
\hline Diarrhea & 15.0 & 15.4 & 21.3 & $0.467(0.592)$ \\
\hline Cough only & 13.2 & 12.2 & 15.6 & $0.281(0.693)$ \\
\hline Malnutrition (weight loss) & 14.0 & 12.3 & 16.6 & $0.308(0.732)$ \\
\hline Fever and cough & 37.8 & 30.7 & 32.5 & $0.256(0.663)$ \\
\hline Diarrhea and malnutrition & 19.7 & 18.9 & 23.7 & I.I87 (0.3II) \\
\hline $\mathrm{n}$ & 401 & $\mathrm{I}, \mathrm{I} 25$ & 417 & \\
\hline
\end{tabular}

Notes: F-statistic is comparable to the chi-square statistic, but is corrected for the design effect of clustering used in the household survey sample design. a Community volunteer only; ${ }^{b}$ community volunteer plus $\mathrm{CHW}$.

Abbreviations: $\mathrm{CHW}$, community health worker; TBA, traditional birth attendant; vs, versus.

for fever/cough increased significantly from $36 \%$ at BHS to $38 \%$ (low-intensity) to $49 \%$ (high-intensity) at FHS ( $t=2.91$ ) and, for diarrhea, from $36 \%$ at BHS to $44 \%$ (control) to $54 \%$ (high-intensity). These increases were uniform across intervention areas, with no significant differences by intervention intensity. Use of antimalarials dropped precipitously from the baseline, when $58 \%$ used them for fever and/or cough and $56 \%$ used them for diarrhea, down to $35 \%$ (control) to $41 \%$ (low-intensity) for fever/cough and 33\% (low-intensity) to $37 \%$ (high-intensity) for diarrhea at follow-up.

\section{Discussion}

This study shows that the multi-pronged intervention, including improvements to facilities, staff, and community engagement, resulted in significant improvements from baseline to follow-up for several of the key $\mathrm{NCH}$ behaviors and outcomes targeted by the program. While newborn and child morbidity remains high in these communities, with almost half of all newborns reported to show one of the danger signs and one-third of young children experiencing an episode of illness in the month prior to the survey, a significantly 
Table 4 Type of care given to sick child in the month preceding the survey by intervention intensity, Northern Nigeria, 2009 and 2011

\begin{tabular}{|c|c|c|c|c|c|c|c|c|c|c|}
\hline \multirow[t]{2}{*}{$\begin{array}{l}\text { Type of care (\%) } \\
\text { ( } \mathrm{n} \text { with any care) }\end{array}$} & \multirow[t]{2}{*}{$\begin{array}{l}2009 \\
\text { Fever/cough } \\
n=1,205\end{array}$} & \multicolumn{3}{|c|}{$\begin{array}{l}20 \mathrm{II} \\
\text { Fever/cough } \\
\mathrm{n}=533\end{array}$} & \multirow[t]{2}{*}{$\begin{array}{l}F(P) \\
C \text { vs L vs H }\end{array}$} & \multirow[t]{2}{*}{$\begin{array}{l}2009 \\
\text { Diarrhea } \\
n=1,335\end{array}$} & \multicolumn{3}{|c|}{$\begin{array}{l}20 \mathrm{II} \\
\text { Diarrhea } \\
\mathrm{n}=348\end{array}$} & \multirow[t]{2}{*}{$\begin{array}{l}F(P) \\
C \text { vs } L \text { vs } H\end{array}$} \\
\hline & & C & $\mathbf{L}$ & $\mathbf{H}$ & & & $\bar{C}$ & $\mathbf{L}$ & $\mathbf{H}$ & \\
\hline \multicolumn{11}{|l|}{ Home care } \\
\hline Gave more fluids & NA & 2.8 & 14.7 & 17.6 & $3.410(0.076)$ & NA & 14.5 & 18.0 & 19.8 & $1.456(0.255)$ \\
\hline Gave ORS & 6.6 & 2.8 & 3.7 & 10.2 & $5.593(0.024)$ & 18.2 & 4.7 & 6.7 & 13.9 & $3.400(0.077)$ \\
\hline Gave cough medicine & NA & 9.9 & 13.7 & 13.6 & I. $122(0.337)$ & NA & 14.0 & 12.3 & 12.3 & $0.144(0.813)$ \\
\hline $\begin{array}{l}\text { Traditional medicine/ } \\
\text { herbs }\end{array}$ & 13.2 & 18.3 & 26.5 & 23.9 & $0.596(0.53 \mathrm{I})$ & 11.6 & 18.6 & 29.5 & 24.6 & I.I $64(0.326)$ \\
\hline Did nothing & 35.2 & 32.7 & 26.5 & 32.3 & I.3I| (0.284) & 40.0 & 28.3 & 29.5 & 27.0 & $0.114(0.87 I)$ \\
\hline \multicolumn{11}{|l|}{ Medication use } \\
\hline Analgesics & 39.0 & 61.9 & 58.3 & 44.4 & $1.869(0.182)$ & 29.9 & 57.1 & 51.4 & 42.3 & $0.902(0.404)$ \\
\hline Antibiotics & 35.9 & 48.8 & 37.5 & 49.0 & $2.108(0.156)$ & 36.2 & 44.0 & 45.0 & 54.2 & $0.643(0.518)$ \\
\hline Antimalarials & 57.5 & 34.6 & 40.5 & 37.0 & $0.332(0.659)$ & 55.8 & 33.3 & 33.3 & 37.1 & $0.096(0.85 I)$ \\
\hline Total sick & 2,910 & 105 & 298 & 130 & & $\mathrm{I}, 4 \mathrm{I} 5$ & 60 & 173 & 89 & \\
\hline
\end{tabular}

Notes: $\mathrm{F}$-statistic is comparable to the chi-square statistic, but is corrected for the design effect of clustering used in the household survey sample design. Bolded values in the 2009 columns indicate that the differences between the BHS and FHS (high- and low-intensity intervention areas only) are significant at the 0.05 significance level or lower, according to the $t$-test. Percentages do not sum to $100 \%$ because multiple care activities may have been used per episode.

Abbreviations: $\mathrm{C}$, control; $\mathrm{H}$, high intensity (community volunteer and community health worker); L, low intensity (community volunteer only); NA, not applicable or data item not collected in the survey; vs, versus; ORS, oral rehydration salts.

larger proportion of women at follow-up had sought advice and responded quickly to their newborn's or child's health crises than at the baseline prior to the implementation of the community engagement and CBSD strategies.

The largest differences in the knowledge of newborn danger signs were achieved by the low-intensity intervention. For most of the indicators of newborn danger signs, mothers who had participated in the community dialogues led by CVs had the same or higher levels of knowledge than mothers who also benefited from the services of a CHW in their community. This is consistent with the program strategy, which is based on a communication model in which changes in knowledge and attitude result from group learning processes, whereby the group learns together and then reinforces for each other the benefits of this new knowledge.

The women exposed to the more intense intervention, with CHWs making home visits and providing direct assistance and support to families in the community, showed a higher degree of mastery of the rapid implementation of responses to challenges to the newborn's health and survival. Although the high-intensity intervention with $\mathrm{CHW}$ s providing communitybased support for improved antenatal, newborn, and sick child care had only been in effect for 1 year, this added level of intervention was sufficient to be associated with greater improvements in immediate breastfeeding, as well as in sustaining the improvements in newborn care already achieved through the $\mathrm{CVs}$ and their community engagement discussions. Those in the high-intensity communities were also more likely to give fluids for fever or cough and ORS for fever/cough or diarrhea. This evidence of a high level of response to child illness is consistent with one of the main messages of the CHWs, who built on the $\mathrm{CV}$ mobilization of communities to observe danger signs by adding the tools and skills necessary to respond appropriately. Of note, the CHWs were trained to recommend modern medications, not traditional ones. Modern medication (analgesics, antibiotics, antimalarials) use did increase in the intervention communities, but also in the control communities, with no significant difference by intervention intensity in the use of traditional medicines or herbs. That there was no statistically significant difference in the use of modern medications among the mothers in the low- versus high-intensity intervention groups suggests that the CHWs concentrated on home care and referral to the primary health care system, as they were trained to do. CHWs also did not distribute drugs, so recommendations for treatment using the WHO Integrated Management of Neonatal and Childhood Illness protocol were not backed up by actual drug availability, so the families would have had to go to the clinic or pharmacist, just like other families in the community.

Another positive result in the study was the increased reliance on CHWs for information about care of the newborn or sick child. At baseline, TBAs checked almost half of all newborns, while, at follow-up, hardly any women took their newborns to TBAs. A similar pattern was observed for seeking advice on the care of sick children, with the intervention group showing increased reliance on the midwives 
and CHWs and less on the TBAs or family and friends. The community dialogues led by the $\mathrm{CVs}$ encouraged women to consult the CHW or the health worker at the closest health facility instead of the TBA, since trained health staff do more to help the mother recognize and respond to any problems that might develop. Thus, they had their newborns or sick infants checked by the midwife or CHW at the health post or during an outreach visit to the community. The availability of midwives or CHWs was the direct result of the program's efforts to place midwives in the intervention clusters and to train CHWs on newborn and sick child care.

This study has several limitations. First, the intervention design was one where the high-intensity intervention with CHWs was an addition to the low-intensity intervention with $\mathrm{CVs}$ only. There were a small number of villages served by a $\mathrm{CHW}$ without the additional support of a CV, but this was too small a number and we are unable to examine the impact of the $\mathrm{CHW}$ contribution independent of the $\mathrm{CV}$ contribution. In future studies, we will be able to include areas with different mixtures of CVs and CHWs. This is particularly important with the introduction of a new cadre of CHWs, namely the village health workers (VHWs), as part of the Nigerian Subsidy Reinvestment and Empowerment Programme (SURE-P) Maternal Child Health Care (MCH) VHW to use oil subsidy money for the reduction of maternal and child mortality. ${ }^{18}$ Second, we did not combine the datasets for an integrated analysis of the behavior change between the baseline and the follow-up, which limits the analysis to a comparison of means and proportions. The pre/post comparison between the BHS and the planned end-of-project survey (May 2013) will include this merger of data, enabling regression analyses to be used to identify the predictors of behavior change and health outcomes. Third, all behaviors and health outcomes are by self-report, with no medical verification of the health events. As in any retrospective self-report, there is likely to be underreporting. We assume that the level of underreporting for the reported events is comparable across both surveys. We did not include the assessment of the child's survival in this study. Future studies need to use a prospective design that will allow assessment of the intervention, its uptake, and its impact on both morbidity and mortality. Fourth, and most importantly, the CHW intervention components were only operational for approximately 1 year prior to the FHS, and hence the period of exposure is more limited for these elements of the intervention. The lack of change for some indicators between the BHS and FHS may therefore be due to limited exposure to the intervention. The end-ofproject survey will permit a longer duration of exposure to be assessed, and it will include a more detailed set of measures of program participation. Fifth, the slight change in the methodology between the 2009 and 2011 surveys, as well as the lack of disaggregated results by intervention and control sites (baseline and follow-up), limits our ability to provide a robust comparison of the results. Lastly, the fact that BHS and FHS respondents were significantly different with respect to their age, level of education, reading and writing in Hausa, and cellphone ownership may make the comparison less robust. However, it is important to note that the health system and sociocultural challenges are deep-rooted, thereby limiting the potential to attenuate the effect of the changes reported here. These limitations notwithstanding, the net result of the changes in understanding about newborn and sick child care were more pronounced in the high- and lowintensity interventions than in control communities.

\section{Conclusion}

The most important conclusion drawn from this study is that much of the improvement in newborn and child care was achieved through the low-intensity intervention, where a trained $\mathrm{CV}$ in each village organized and led community dialogues on a series of maternal and newborn care topics. They encouraged discussion about health problems and used songs and role-plays to help their fellow villagers learn about danger signs and how to prevent them and, if seen, how to respond to them. They encouraged the women to trust the health workers at the health post, who they knew had been recently trained by the program and were eager to serve the village. The addition of the CHWs in the high-intensity intervention communities solidified this trust and reinforced the messages of prevention and appropriate treatment, but it is clear that their work built upon that of the CVs. This was how the program was designed, and our results suggest that the strategy of $\mathrm{CV}$ plus $\mathrm{CHW}$ is working.

As the program expands into the remaining LGAs and incorporates additional CHWs, both the CBSD model described here and the VHW model being introduced through SURE-P, it will be important to integrate them into a team, which is the direction suggested by our results. This means working out the different roles that the CVs, VHWs, and CHWs play in promoting the improvement of $\mathrm{MNCH}$ outcomes in these villages, and then assuring that our monitoring system enables us to track their contributions and the outcomes from their individual and collective efforts. While we were not able to disaggregate our data sufficiently to permit an analysis of the impact of the CVs and CHWs 
on maternal and infant mortality, in the future it will be important to assess which combinations of CHWs enable the greatest reductions in mortality.

\section{Acknowledgments}

This research was conducted as part of the Programme for Reviving Routine Immunization in Northern NigeriaMaternal Newborn and Child Health (PRRINN-MNCH), which is funded by UKaid (Department for International Development) and the Norwegian Government. The authors acknowledge the support of the community leaders and respondents who participated in this study. We also acknowledge the support of Dr Rodion Kraus, Deputy National Program Manager, and Dr Anthony Aboda, Maternal Newborn and Child Health Advisor, for leading the design of some of the interventions reported here.

\section{Author contributions}

SEF, HVD, CG, FA, and GYA participated in the conception of the study; OTU assisted with the analysis; CG, FA, and GYA assisted with interpretation of the results. All authors drafted and revised the manuscript, and also read and approved the final version.

\section{Disclosure}

The authors report no conflicts of interest in this work.

\section{References}

1. Alkema L, You D. Child mortality estimation: a comparison of UN IGME and IHME estimates of levels and trends in under-five mortality rates and deaths. PLoS Med. 2012;9(8):e1001288.

2. Jones G, Steketee RW, Black RE, Bhutta ZA, Morris SS; Bellagio Child Survival Study Group. How many child deaths can we prevent this year? Lancet. 2003;362(9377):65-71.

3. UNICEF. The State of the World's Children Special Edition: Celebrating 20 Years of the Convention on the Rights of the Child. New York: UNICEF; 2009. Available from: http://www.unicef.org/publications/files/ SOWC_Spec._Ed._CRC_Main_Report_EN_090409.pdf. Accessed September 13, 2013.

4. Bhutta ZA, Ali S, Cousens S, et al. Alma-Ata: Rebirth and Revision 6 Interventions to address maternal, newborn, and child survival: what difference can integrated primary health care strategies make? Lancet. 2008;372(9642):972-989.
5. Bhutta ZA, Chopra M, Axelson H, et al. Countdown to 2015 decade report (2000-10): taking stock of maternal, newborn, and child survival. Lancet. 2010;375(9730):2032-2044.

6. Bhutta ZA, Darmstadt GL, Hasan BS, Haws RA. Community-based interventions for improving perinatal and neonatal health outcomes in developing countries: a review of the evidence. Pediatrics. 2005;115(Suppl 2):519-617.

7. Kinney MV, Kerber KJ, Black RE, et al; Science in Action: Saving the lives of Africa's Mothers, Newborns, and Children working group, Axelson H, Bergh AM, et al. Sub-Saharan Africa's mothers, newborns, and children: where and why do they die? PLoS Med. 2010;7(6): e1000294.

8. Guilbert JJ. The World Health Report 2006: working together for health. Educ Health (Abingdon). 2006;19(3):385-387.

9. Wirth ME, Balk D, Delamonica E, Storeygard A, Sacks E, Minujin A. Setting the stage for equity-sensitive monitoring of the maternal and child health Millennium Development Goals. Bull World Health Organ. 2006;84(7):519-527.

10. Christopher JB, Le May A, Lewin S, Ross DA. Thirty years after Alma-Ata: a systematic review of the impact of community health workers delivering curative interventions against malaria, pneumonia and diarrhoea on child mortality and morbidity in sub-Saharan Africa. Hum Resour Health. 2011;9(1):27.

11. Chopra M, Sharkey A, Dalmiya N, Anthony D, Binkin N. Strategies to improve health coverage and narrow the equity gap in child survival, health, and nutrition. Lancet. 2012;380(9850):1331-1340.

12. [No authors listed]. Strengthening the performance of community health workers in primary health care. Report of a WHO Study Group. World Health Organ Tech Rep Ser. 1989;780:1-46.

13. Lewin S, Lavis JN, Oxman AD, et al. Supporting the delivery of costeffective interventions in primary health-care systems in low-income and middle-income countries: an overview of systematic reviews. Lancet. 2008;372(9642):928-939.

14. Nigeria Demographic and Health Survey 2008 Report. Abuja: National Population Commission, Calverton, MD: ICF Macro; 2009.

15. State Population [webpage on the Internet]. Wuse Abuja: National Population Commission, Nigeria. Available from: http://www.population.gov. ng/index.php/state-population. Accessed September 13, 2013.

16. World Health Organization. Monitoring Emergency Obstetric Care: A Handbook. Geneva, Switzerland: World Health Organization; 2009.

17. World Health Organization. Immunization coverage cluster survey Reference manual. Geneva: WHO Vaccine Assessment and Monitoring Team, Department of Immunization, Vaccines and Biologicals; 2005. Available from: http://whqlibdoc.who.int/hq/2005/who_ivb_04.23.pdf. Accessed September 13, 2013.

18. The Presidency Federal Republic of Nigeria SURE-P [homepage on the Internet]. Nigeria: Federal Republic of Nigeria; 2012. Available from: http://www.sure-p.gov.ng/. Accessed September 13, 2013.
International Journal of Women's Health

\section{Publish your work in this journal}

The International Journal of Women's Health is an international, peerreviewed open-access journal publishing original research, reports, editorials, reviews and commentaries on all aspects of women's healthcare including gynecology, obstetrics, and breast cancer. The manuscript management system is completely online and includes

\section{Dovepress}

a very quick and fair peer-review system, which is all easy to use. Visit http://www.dovepress.com/testimonials.php to read real quotes from published authors. 